\title{
Endoscopic ultrasound-guided gastrojejunostomy-assisted ERCP in a Billroth II gastrectomy patient
}

An 85-year-old man who had previously undergone a Billroth II gastrectomy was admitted because of biliary sepsis due to choledocholithiasis. An urgent percutaneous cholecystostomy was performed and endoscopic retrograde chol- angiopancreatography (ERCP) was requested. The afferent limb was however not accessible with either the duodenoscope or a therapeutic gastroscope because of the sharp angulation and a long afferent limb ( $\triangleright$ Fig.1 a). An 8.5-Fr naso-
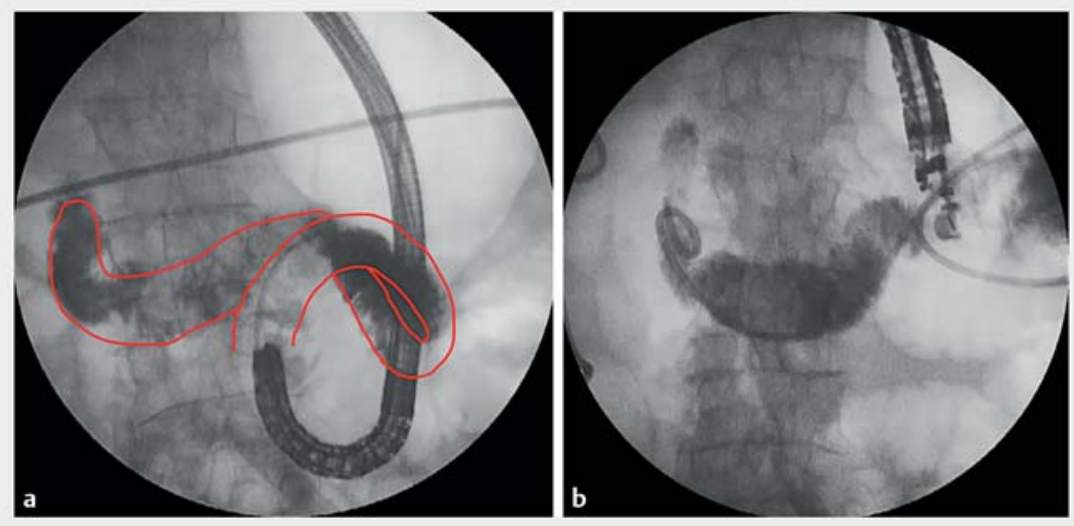

- Fig. 1 Radiographic images during endoscopic retrograde cholangiopancreatography showing: $\mathbf{a}$ the afferent limb; $\mathbf{b}$ an 8.5-Fr nasobiliary tube in the afferent limb.
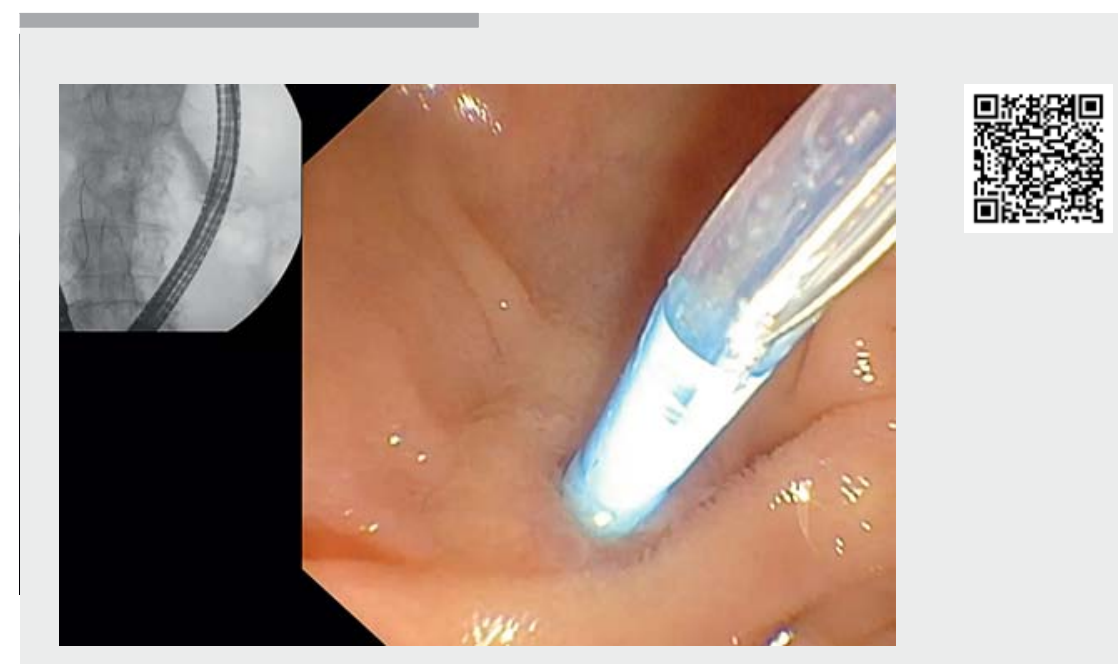

$\checkmark$ Video 1 The steps performed during endoscopic ultrasound (EUS)-guided gastrojejunostomy-assisted endoscopic retrograde cholangiopancreatography (ERCP) including a nasobiliary tube being advanced to the afferent limb to distend it with contrast and methylene blue, following which an EUS-guided gastrojejunostomy was performed with a $15 \times$ 10-mm lumen-apposing metal stent (LAMS; Hot Axios), which subsequently allowed ERCP to be performed through the LAMS, leading to successful stone fragmentation and extraction.

biliary tube was advanced into the afferent limb to distend it with contrast and

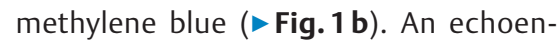
doscope was then introduced and, after the afferent limb closest to the papilla had been identified ( $>$ Fig.2), an endoscopic ultrasound-guided gastrojejunostomy (EUS-GJ) was performed using a $15 \times 10$-mm lumen-apposing metal stent (LAMS; Hot Axios; Boston Scientific, Natick, Massachusetts, USA) (> Fig.3).

A week later an ERCP was performed through the LAMS (> Fig.4). Sphincterotomy was performed with a sphincterotome (Autotome; Boston Scientific) rotated $180^{\circ}$. Several stones were extracted; however, one was impacted at the papilla. An electrohydraulic lithotripsy (EHL) probe was introduced through the extractor balloon and fragmentation of the stone was performed while saline was injected continuously. Fragmentation of the stones was completed using an intraductal cholangioscope (SpyGlass; Boston Scientific) and, following 15-mm papillary large-balloon dilation, all of the stones were successfully removed ( $\triangleright$ Video 1 ).

In patients with previous gastric surgery, such as Roux-en-Y gastric bypass, EUS-G] has been shown to be effective for access to the bile duct, with greater technical and clinical success than ERCP by enteroscopy [1]. To date, its use in patients with a Billroth II gastrectomy has not been de-

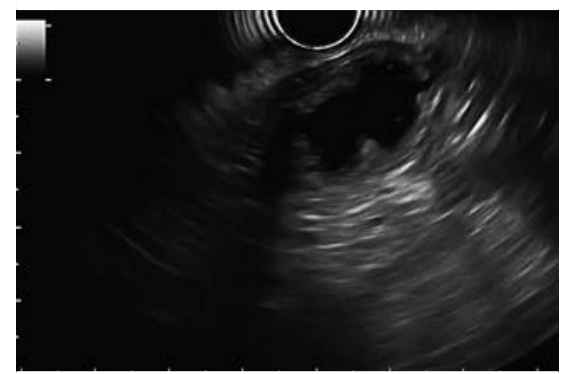

- Fig. 2 Endoscopic ultrasound image showing the afferent limb distended with saline, methylene blue, and contrast. 


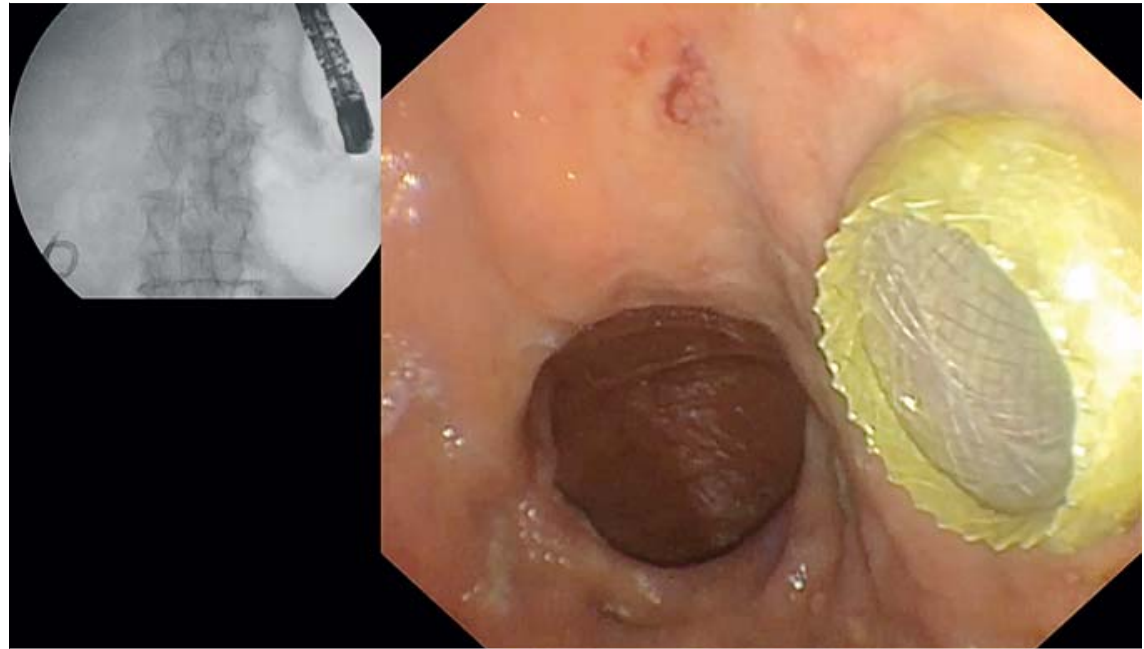

- Fig. 3 Endoscopic image (inset radiographic image) showing the lumen-apposing metal stent in the stomach forming a gastrojejunostomy.

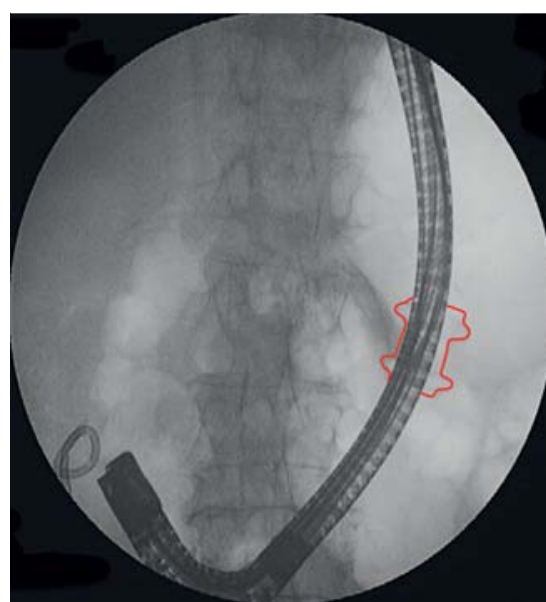

Fig. 4 Radiographic image during the second endoscopic retrograde cholangiopancreatography procedure a week later showing the duodenoscope passing through the lumen-apposing metal stent. scope moving beyond the entrance to the limb. In this context, the creation of a bridging EUS-G] allowed the performance of ERCP successfully and without adverse effects.

Endoscopy_UCTN_Code_TTT_1AS_2AD

\section{Competing interests}

Dr. Aparicio Tormo has provided consultancy services for Boston Scientific.

\section{The authors}

\section{Belén Martínez-Moreno, Juan Antonio}

Casellas, José Ramón Aparicio Tormo

Endoscopy Unit, Hospital General Universitario de Alicante, Alicante, Spain

\section{Corresponding author}

scribed. In most cases, access to the afferent limb is possible by duodenoscope, therapeutic gastroscope, or enteroscope [2]; however, in some cases this is not possible. In our patient, the sharp angle, in addition to the length of the limb, prevented the duodenoscope or the gastro-

\section{José Ramón Aparicio Tormo, MD}

Endoscopy Unit, Hospital General

Universitario de Alicante, Avda. Pintor Baeza

s/n, 03013 Alicante, Spain

japariciot@gmail.com

\section{References}

[1] Bukhari M, Kowalski T, Nieto J et al. An international, multicenter, comparative trial of EUS-guided gastrogastrostomy-assisted ERCP versus enteroscopy-assisted ERCP in patients with Roux-en-Y gastric bypass anatomy. Gastrointest Endosc 2018; 88: 486-494

[2] Park TY, Song T]. Recent advances in endoscopic retrograde cholangiopancreatography in Billroth II gastrectomy patients: A systematic review. World J Gastroenterol 2019; 25: 3091-3107

\section{Bibliography}

DOI https://doi.org/10.1055/a-1022-4453

Published online: 25.10 .2019

Endoscopy 2020; 52: 306-307

(c) Georg Thieme Verlag KG

Stuttgart · New York

ISSN 0013-726X

\section{ENDOSCOPY E-VIDEOS}

https://eref.thieme.de/e-videos

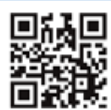

Endoscopy E-Videos is a free access online section, reporting on interesting cases and new

techniques in gastroenterological endoscopy. All papers include a high quality video and all contributions are freely accessible online.

This section has its own submission website at https://mc.manuscriptcentral.com/e-videos 